\title{
Understanding the Large Negative Impact of Oil Shocks*
}

\author{
Luís Aguiar-Conraria \\ Professor Auxiliar \\ NIPE, Universidade do Minho \\ Portugal \\ aguiarconraria@gmail.com
}

\author{
Yi Wen \\ Research Officer \\ Federal Reserve Bank of St. Louis \\ USA \\ yi.wen@stls.frb.org
}

February 14, 2006

\begin{abstract}
This paper offers a plausible explanation for the close link between oil prices and aggregate macroeconomic performance in the 1970s. Although this link has been well documented in the empirical literature, standard economic models are not able to replicate this link when actual oil prices are used to simulate the models. In particular, standard models cannot explain the depth of the recession in 1974-75 and the strong revival in 1976-78 based on the oil price movements in that period. This paper argues that a missing multiplier-accelerator mechanism from standard models may hold the key.
\end{abstract}

Keywords: Oil Prices; Real Business Cycle; Capacity Utilization; Externalities; Monopolistic Competition; Multiplier-Accelerator.

JEL classification: E32, E37, E22.

\footnotetext{
*We thank Karl Shell, Deborah Kerley, John McAdams, participants at the Cornell-Penn State Macro Conference (Fall 2004), two anonymous referees and the editor, Ken West, for helpful comments. Luís AguiarConraria acknowledges financial support from Fundação para a Ciência e a Tecnologia, grant SFRH-BD4982-01. The views expressed in the paper and any remaining errors are the authors' alone. Correspondence: Yi Wen, Research Department, Federal Reserve Bank of St. Louis, P.O. Box 442, St. Louis, MO 63166. E-mail: yi.wen@stls.frb.org.
} 


\section{Introduction}

A large body of empirical literature has suggested that oil price shocks have an important effect on economic activity. This literature has convincingly argued that oil prices were both significant determinants of U.S. economic activity and exogenous to it in the post-war period. ${ }^{1}$ However, despite 30 years of research since the first major post-war oil crisis in 1973-74, how exactly can oil shocks cause a severe economic recession still remains an open question. Imported oil as an input for the entire U.S. economy accounted for roughly one to two percent of the total production cost in the early 1970s. Based on this cost share, and assuming constant returns to scale, even a $100 \%$ increase in the price of oil can only translate into an approximately one to two percent decrease in output, notwithstanding the likely counter effects from factor substitutions. Yet the actual decline in output following the 1973 oil crisis, which caused a roughly 80 percent increase in the price of imported oil, was about seven to eight percent from its peak. A strong multiplier is clearly missing in standard models.

Standard economic theory not only substantially under-predicts the contraction of output following the oil shocks in 1973-74, but also fails to explain the revival of the U.S. economy starting in the middle of 1975 despite the continuing rise in the oil price level in that period. Standard theory predicts an immediate, permanent drop in output after a permanent increase in oil prices, while empirical studies show that output undergoes a U-shaped transitional path after a permanent oil shock. ${ }^{2}$ For example, real GDP dropped by only 2 percent on impact in 1974, and the contraction continued for nearly 5 more quarters until 1975. Also, despite oil prices remaining high and continuing to rise throughout the late 1970s, the U.S. economy started to recover in the middle of 1975, and by the end of 1977 real GDP was already back to its potential trend level. Such a dramatic recovery after a nearly permanent oil price increase is not predicted by standard general equilibrium models.

Figure 1 illustrates these multiplier-accelerator effects after the oil price increases in late 1973. In the top panel, the solid line represents the log price of imported oil, and the dashed lines represent percentage changes of the oil price. In the middle panel, the solid line represents fluctuations in GDP relative to its trend (defined by the HP filter). In the 4th quarter of 1973 and the first quarter of 1974, when the oil price increased sharply (nearly doubled), real GDP dropped by only two percent, consistent with the prediction of a standard economic model. However, the contraction continued during the entire year of 
1974. A trough was not reached until 5 quarters later in early 1975, and by then real GDP had declined more than seven percent from its pre-shock level. Also notice the revival in 1975. Within 3 years, the U.S. economy was almost back to its pre-shock level again by the 4th quarter of 1978, despite oil prices remaining high and continuing to rise throughout that period.

Another striking aspect of the 1974-75 recession is that fixed investment suffered the severest hit both absolutely and relative to output. Based on HP-filtered data (the bottom panel in Figure 1), the fall in investment during an average recession prior to the 1973 oil shock was about 20\% from peak to trough. During 1974-75, however, investment fell by more than $35 \%$ from its peak. Furthermore, the standard deviation of investment was about 4.4 times that of output prior to the 1973 oil shock. This volatility ratio increased to 7.1 during the 1973 oil shock period. In contrast, the ratio of the standard deviation of non-durable goods consumption to GDP was about 0.54 prior to the 1973 oil shock, and became 0.31 during the oil shock period.

Thus, there are several major puzzles associated with the 1975 recession following the oil shock in 1973-74:

1). Why was the recession so deep - much deeper than predicted by standard models?

$2)$. Why was the trough of the recession delayed for 4-6 quarters?

3). Why was there a strong recovery in economic activity in 1976-78 despite oil prices remaining high and continuing to rise during the entire period?

4). Why did investment suffer the severest hit during that period compared to other components of GDP?

The first puzzle has already drawn a substantial amount of attention. But the last three puzzles have rarely been emphasized in the theoretical literature. Hamilton and Herrera (2004) stress that explaining the delay of the effects of oil price shocks is an important challenge for theory: “(...) the greatest effects of an oil shock do not appear until three or four quarters after the shock. Investigating the cause of this delay would seem to be an important topic for research" (Hamilton and Herrera 2004, p.281).

Oil shocks have been assigned a prominent role in contemporary macroeconomic textbooks and models as examples of supply-side disturbances. This includes the modern version of the IS-LM model (see, e.g., Abel and Bernanke 2001) and the neoclassical business-cycle models (see, e.g., Hamilton 1988a). Yet, when actual oil prices are used for simulations, standard economic models cannot explain the deep recession in 1974-75 and the strong recovery in 1976-78 by the oil increase in 1973-74. Kim and Loungani (1992), for example, argue that 
standard models can account for at most 16-35 percent of the reduction in output during the oil crises in 1973-74. The key for the failure is the lack of a strong multiplier-accelerator mechanism in standard models to amplify and propagate the impact of oil shocks throughout the economy.

For this reason, Barsky and Kilian (2001) argue that the recession in 1974-75 and the subsequent recovery in 1976-78 may have nothing to do with the oil shocks in 1973-74. Instead, they argue that the expansionary monetary policies conducted in the early 1971-72 were responsible for the recession in 1974-75 and the inflation in 1975-76. Their argument is based on a multiplier-accelerator monetary transmission mechanism. This mechanism generates an economic boom after the expansionary monetary policy in the early 1970s, and it was this boom that planted the seed for its own destruction in the mid-1970s. While intriguing, this argument remains a speculation unless quantitative simulations using actual money supply data can be conducted based on their theoretical model so as to show that the simulated time series replicate the U.S. data. ${ }^{3}$

To search for the missing multiplier on the real side of the economy, Rotemberg and Woodford (1996) argue that monopolistic competition is responsible for amplifying the impact of the oil shock. Finn (2000), however, disputes this theory by arguing that perfect competition can also account for the depth of the recession if firms' capacity utilization rate is allowed to vary in response to the oil shock. Neither of these models, however, is able to explain the accelerator effect of the oil shock: the greatest effects of the oil shock do not appear until several quarters after the shock, and a strong recovery is observed within a couple of years despite oil prices remaining high. If actual oil prices are used in simulations, then following the sharp increase in oil prices in 1973-74, both Finn's and Rotemberg and Woodford's models predict an immediate recession that will last throughout the entire 1970s without recovery. Such a prediction contradicts what we see in Figure 1.

This paper proposes a model to explain the multiplier-accelerator effect of oil shocks on the U.S. economy in the 1970s. Our explanation builds on the insights of Rotemberg and Woodford (1996) and Finn (2000), and is closely related to the suggestion of Hamilton (1988a, 1988b and 2003). According to Hamilton, the oil crisis in 1973-1974 affected the aggregate economy mainly by depressing aggregate demand, such as consumption and investment. In this paper we focus on investment demand. One possible way to model such a demand-side effect on investment is to allow for externalities among firms. Due to externalities among firms, the strength of aggregate demand facing an intermediate goods producer is a function of the production level of other firms. Thus, when the oil crisis hit the U.S. economy, 
contractions in economic activity at each firm reinforced each other via the externalities, giving rise to a strong multiplier effect. The same force of interdependence and reinforcement among firms' production decisions also caused the economy to over-shoot when converging to the steady state, resulting in cyclical fluctuations. Such a cyclical propagation mechanism is responsible for the temporary revival of the U.S. economy in 1976-78. Thus we show that the recession in 1974-75 and the recovery in 1976-78 can be fully rationalized by the oil price increase in 1973-74 alone, without the need to resort to other unobserved shocks in that period. This prediction is also consistent with our VAR analysis of the impact of oil shocks on the U.S. economy in that period.

Despite the improvement of our model over the existing models in explaining the business cycle in the 1970s, there are obvious limitations to our model as well. Like existing general equilibrium models (such as those of Finn 2000 and Rotemberg and Woodford 1996), our model implies symmetric effects of oil shocks. In the data, however, the effects of oil shocks appear to be highly asymmetric in that increases in oil prices tend to impact the U.S. economy far more significantly than decreases in oil prices (see, e.g., Hamilton 2003 and Mork 1989). Starting around the mid-80s, decreases in oil prices were as frequent as increases. A structural change in the relation between oil and the rest of the economy in the 1980s has been extensively documented by many authors (see, e.g., Mork 1989, Hamilton 1996 and 2003, Hooker 1996 and 2002). For this reason, we stop our analysis at the period before the mid-80s because our model is not suitable for analyzing the effects of the negative oil shocks after the mid-80s. However, we do extend our analysis to cover the second major oil crisis in 1979-80.

The rest of the paper is organized as follows. Section 2 presents the model and its empirical predictions. Section 3 provides circumstantial empirical evidence to support the predictions of our model. Section 4 extends the analysis to the second oil shock period between 1979 and 1984. Section 5 concludes the paper.

\section{The Model}

The model we study is a slightly modified version of the model of Wen (1998). There are two types of goods in the economy, final goods and intermediate goods. The final good sector is competitive and uses intermediate goods to produce output according to the technology,

$Y=\left(\int_{i=0}^{1} y_{i}^{\lambda} d i\right)^{1 / \lambda}$, where $\lambda \in(0,1)$ measures the degree of factor substitutability among the intermediate goods (the exact elasticity of substitution is $1 /(1-\lambda)$ ). Let $p_{i}$ be the relative 
price of intermediate good $i$ in terms of the final good. Profits of a final good producer are given by $\Pi=Y-\int_{i=0}^{1} p_{i} y_{i} d i$. The price of the final good is normalized to one. Profit maximization leads to the inverse demand function for intermediate goods, $p_{i}=Y^{1-\lambda} y_{i}^{\lambda-1}$.

Assume that each intermediate-good-producing firm $i$ is a monopolist specializing in producing good $i$. The technology for producing intermediate goods is given by $y_{i}=$ $\left(e_{i} k_{i}\right)^{a_{k}} n_{i}^{a_{n}} O_{i}^{a_{o}}$, where $e \in[0,1]$ denotes the capacity utilization rate, $k$ denotes capital stock, $n$ denotes labor, and $o$ denotes oil. We assume that oil cannot be domestically produced and the elasticities satisfy $\left\{a_{o}, a_{k}, a_{n}\right\} \in[0,1]$ and $\left(a_{k}+a_{n}+a_{o}\right) \geq 1$, indicating possible increasing returns to scale at the firm level. Assuming that firms are price takers in the factor markets, the profits of firm $i$ are then given by $\pi_{i}=p_{i} y_{i}-\left(r+\delta_{i}\right) k_{i}-w n_{i}-p^{o} o_{i}$, where $\left(r+\delta_{i}\right)$ denotes the user's cost of capital, $w$ denotes real wage, and $p^{o}$ denotes the real price of imported oil. Notice that factor prices are common to all firms. Each firm's capital depreciation rate is assumed to depend on its capacity utilization rate, $\delta_{i}=(1 / \theta) e_{i}^{\theta}$, where $\theta>1$. Since intermediate good producers are monopolists facing downward sloping demand curves, their profit functions can be rewritten as $\pi_{i}=Y^{1-\lambda} y_{i}^{\lambda}-\left(r+\delta_{i}\right) k_{i}-w n_{i}-p^{o} o_{i}$, which is concave as long as $\lambda\left(a_{k}+a_{n}+a_{o}\right) \leq 1$. Profit maximization by each intermediate-good-producing firm leads to the following first order conditions: $e_{i}^{\theta-1} k_{i}=\lambda a_{k} p_{i} y_{i} / e_{i}, r+\delta_{i}=\lambda a_{k} p_{i} y_{i} / k_{i}, w=\lambda a_{n} p_{i} y_{i} / n_{i}$, and $p^{o}=\lambda a_{o} p_{i} y_{i} / o_{i}$. In a symmetric equilibrium, we have $n_{i}=n, k_{i}=k, e_{i}=e, \delta_{i}=\delta$, $o_{i}=o, y_{i}=y=Y, \pi_{i}=\pi$, and $p_{i}=1$.

A representative consumer in the economy maximizes expected life-time utility,

$$
E_{0} \sum_{t=0}^{\infty} \beta^{t}\left(\log c_{t}-b \frac{n_{t}^{1+\gamma}}{1+\gamma}\right)
$$

subject to $c_{t}+s_{t+1}=\left(1+r_{t}\right) s_{t}+w_{t} n_{t}+\pi_{t}$, where $s$ denotes aggregate savings. Since the aggregate factor payment for oil, $p^{o} o$, goes to foreigners, it is not included in the consumer's income. The first order conditions for utility maximization with respect to labor supply and savings are given, respectively, by $b n_{t}^{\gamma}=w_{t} / c_{t}$ and $1 / c_{t}=\beta E_{t}\left\{\left(1+r_{t+1}\right) / c_{t+1}\right\}$. In equilibrium, $s_{t}=k_{t}$ and factor prices equal their marginal products.

By substitutions using the equilibrium factor demand functions for oil and the capacity utilization rate, the production function can be reduced to

$$
y_{t}=\phi\left(\frac{1}{p_{t}^{o}}\right)^{\frac{a_{o} \tau_{n}}{1-a_{o} \tau_{n}}} k_{t}^{\frac{a_{k} \tau_{k}}{1-a_{o} \tau_{n}}} n_{t}^{\frac{a_{n} \tau_{n}}{1-a_{o} \tau_{n}}}
$$


where $\phi$ is a positive constant, $\tau_{n} \equiv \theta /\left(\theta-a_{k}\right)>1$, and $\tau_{k} \equiv(\theta-1) /\left(\theta-a_{k}\right)<1$. After rewriting the production function in this way, we can notice several things. First, the oil price serves as an adverse productivity shock in the model $\left(A_{t}=1 / p_{t}^{o}\right)$. In particular, the larger the cost share of oil, $a_{o}$, the larger the impact an oil price shock has on total factor productivity (since $a_{o} \tau_{n} /\left(1-a_{o} \tau_{n}\right)$ increases with $\left.a_{o}\right)$. In addition, the cost share of oil enhances the output elasticity of labor (since $a_{n} \tau_{n} /\left(1-a_{o} \tau_{n}\right)$ also increases with $\left.a_{o}\right)$. Second, capacity utilization amplifies the impact of oil shocks. Capacity utilization introduces a new term, $\tau_{n}=\theta /\left(\theta-a_{k}\right)>1$, into the output elasticities with respect to $p^{o}$ and $n$. Thus, capacity utilization magnifies the impact of an oil shock via two channels: a direct channel, via its positive effect on the output elasticity of total factor productivity, and an indirect channel, via its positive effect on the output elasticity of labor. Third, capacity utilization enhances returns to scale if $a_{k}+a_{n}+a_{o}>1$, because $\gamma_{k}+\gamma_{n} \geq a_{k}+a_{n}+a_{o}$, with equality only if $a_{k}+a_{n}+a_{o}=1 .^{4}$

The model can be solved by log-linearizing the first order conditions around the steady state. It is shown by Wen (1998) and Aguiar-Conraria and Wen (2004) that with very mild externalities, this model possesses multiple dynamic equilibria around a unique steady state. In particular, equilibrium output and the capital stock in the model follow the following dynamic process (circumflex variables denote percentage deviations from the steady state values):

$$
\left(\begin{array}{c}
\hat{y}_{t} \\
\hat{k}_{t}
\end{array}\right)=M\left(\begin{array}{c}
\hat{y}_{t-1} \\
\hat{k}_{t-1}
\end{array}\right)+R_{1} E_{t-1} \hat{p}_{t}+R_{2} \hat{p}_{t-1}+\left(\begin{array}{c}
1 \\
0
\end{array}\right) \Theta_{t},
$$

where $M$ is a full-rank matrix with both eigenvalues lying inside the unit circle on the complex plane, and $\Theta_{t+1}$ is a one-step-ahead forecasting error of output, defined as $\Theta_{t}=\hat{y}_{t}-E_{t-1} \hat{y}_{t}$, which satisfies $E_{t} \Theta_{t+1}=0$ for all $t$. The forecast error may serve as a source of sunspots or animal spirits in this model when indeterminacy arises. ${ }^{5}$ In this paper, we assume there are no sunspots by setting $\Theta=0$. This implies that the indeterminacy of the initial output level, given the state $\left\{\hat{k}_{0}, p_{0}\right\}$, can be resolved by setting $\hat{y}_{0}=0 .{ }^{6}$

\subsection{Calibration}

We calibrate the model using the following parameter values, which are standard in the literature for quarterly models: $\gamma=0$ (indivisible labor), $\beta=0.99$, and $\theta=1.4$ (implying a steady-state rate of $\delta=0.025)$. Since the model can be mapped into a perfectly competi- 
tive model with aggregate production externalities, we calibrate the technology parameters, $\left\{\lambda, a_{k}, a_{n}, a_{o}\right\}$, according to an externality version of the model. Denote the externality parameter for production by $\eta$; in a symmetric equilibrium the aggregate version of the intermediate sector's production function can then be written as

$$
y_{t}=\left(e_{t} k_{t}\right)^{\alpha_{k}(1+\eta)} n_{t}^{\alpha_{n}(1+\eta)} o_{t}^{\left(1-\alpha_{k}-\alpha_{n}\right)(1+\eta)},
$$

where the aggregate returns to scale are given by $1+\eta$. This model is equivalent to the monopolistic competition model if $\lambda(1+\eta)=1, a_{k}=\alpha_{k}(1+\eta), a_{n}=\alpha_{n}(1+\eta)$, and $a_{o}=\left(1-\alpha_{k}-\alpha_{n}\right)(1+\eta)$. Thus, we can calibrate the output elasticity parameters in the production function according to each production factor's cost share in output. Following the existing literature (e.g., Benhabib and Farmer 1994 and Wen 1998), we set labor's share $\alpha_{n}=0.7$. Nordhaus (2002) estimates imported oil's share in GDP for the post-war period to be about one percent (with a standard error of 0.67 percent). Rotemberg and Woodford (1996, p. 564-565) also suggest that imported oil accounts for about 1.6 percent of GDP. Hence we set oil's share $\alpha_{o}=0.015$ as our benchmark. This implies capital's share $\alpha_{k}=$ 0.285. Laitner and Stolyarov (2004) recently re-estimated the aggregate returns to scale for the U.S. economy. Their robust estimate of returns to scale is in the range of 1.09 to 1.11. We choose $\eta=0.108$, which is in line with their estimates. This implies a markup of around 11 percent $(1 / \lambda=1+\eta \approx 1.11)$ in the monopolistic version of our model.

We also need to assume a stochastic process for the oil price in order to compute the equilibrium decision rules, which are functions of the forecasts of future oil prices, $E_{t} p_{t+j}$, for all $j \geq 0$. Based on both the Dickey-Fuller test and the Augmented Dickey-Fuller test, we cannot reject the hypothesis of a unit root in oil prices for either the entire post-war sample (1950:1-2003:4) or the sample period we use (1950:1-1978:4). Further econometric analyses suggest that the oil price can be reasonably characterized as following a random walk. The random walk assumption is also consistent with our empirical VARs in Section 3. The calibrated parameters are summarized in Table 1.

\subsection{Predictions}

Before presenting the predictions of our model, we first present the predictions of standard models so as to highlight the importance of the multiplier-accelerator mechanism missing in standard models. The predictions of a model with constant returns to scale $(\eta=0)$, perfect competition $(\lambda=1)$, and fixed capacity utilization $(e=1)$ are presented as Model 1 in Figure 
2 (and a close up in Figure 2-1), where the solid lines represent U.S. data and the dashed lines represent the model. They show that the standard model cannot generate a significant recession after the oil shock in 1974. The recession in the model is barely observable. Output contracts by only two percent in the model after a near doubling of the oil price in 1974, while the actual contraction is about eight percent in the data (see Figure 2-1 for a close up).

Allowing for capacity utilization can greatly magnify the impact of oil shocks. This can be seen from the predictions of Finn's (2000) capacity utilization model presented as Model 2 in Figure 2 and Figure 2-1 (dot-dashed lines). These figures show that Finn's model is able to match the depth of the 1975 recession in output. This is attributable to a variable capacity utilization that amplifies the impact of the oil shocks. However, the model still fails to match the data on several grounds. First, it predicts an immediate, permanent recession after the oil shock in 1973, failing to explain the gradualness of the recession in 1974-75 and the recovery in 1975-78. Second, the model cannot match the depth of the recession in investment and employment, and it over-predicts the depth of the recession in consumption. Furthermore, the model fails to predict the delay of the recession in employment by several quarters. Among these failures, the failure to match the U-shaped transitional dynamics of the recession is the most striking. ${ }^{7}$

Figure 3 and Figure 3-1 (a close up) show that our model improves the predictions of the standard models substantially on several grounds. First, it can predict not only the depth of the 1975 recession in U.S. output, but also the depth of the recession in investment and employment. Second and most strikingly, the model is able to predict the U-shaped transitional dynamics seen in the data. For example, the model predicts that the trough of the recession is delayed by 4-6 quarters after the oil price increase in late 1973, and that there will be a recovery in 1976-78. The model tends to under-predict the recession in consumption and over-predict the recession in employment. Overall, however, the improvements of the model over the standard models are significant.

\subsection{Dissecting the Multiplier-Accelerator Effect}

The reason for the model's success lies in a multiplier-accelerator mechanism emerging under externalities (or monopolistic competition with increasing returns to scale). This mechanism gives rise to dampened cycles. To understand the multiplier-accelerator mechanism, recall that the reduced-form production function is given by Equation (2). If, on the other hand, 
we use the externality version of the model by setting $a_{o}=\alpha_{o}(1+\eta), a_{k}=\alpha_{k}(1+\eta)$, $a_{n}=\alpha_{n}(1+\eta)$, and $\alpha_{o}+\alpha_{k}+\alpha_{n}=1$, the reduced-form aggregate production function can be written as

$$
y_{t}=\phi\left(\frac{1}{p_{t}^{o}}\right)^{\frac{\alpha_{o}(1+\eta) \tau_{n}}{\left.1-\alpha_{o}(1+\eta)\right) \tau_{n}}} k_{t}^{\frac{\alpha_{k}(1+\eta) \tau_{k}}{1-\alpha_{o}(1+\eta) \tau_{n}}} n_{t}^{\frac{\alpha_{n}(1+\eta) \tau_{n}}{1-\alpha_{o}(1+\eta) \tau_{n}}}
$$

where $\tau_{n} \equiv \theta /\left[\theta-\alpha_{k}(1+\eta)\right], \tau_{k} \equiv(\theta-1) /\left[\theta-\alpha_{k}(1+\eta)\right]$.

Suppose there are no externalities $(\eta=0)$ and there is no variable capacity utilization $\left(\theta=\infty\right.$ and $\left.\tau_{n}=\tau_{k}=1\right)$. Then the output elasticity of the oil price is given by $-\alpha_{o} /\left(1-\alpha_{o}\right)$, and the output elasticity of labor is given by $\alpha_{n} /\left(1-\alpha_{o}\right)$. Based on our calibration of oil's share in production, the oil elasticity is 0.015 and the labor elasticity is 0.71 , suggesting that a doubling of the oil price (a 100\% increase) translates to less than a $1.5 \%$ change in output, holding labor constant. Since a higher oil price decreases labor's productivity, employment will also decrease, amplifying the impact of oil price on output. For simplicity, assume that labor decreases by $1 \%$. Then there will be an additional $0.71 \%$ change in output. The total output change is thus about $2.2 \%$.

If capacity utilization is variable, then the oil price elasticity is given by $-\alpha_{o} \tau_{n} /(1-$ $\left.\alpha_{o} \tau_{n}\right)=-0.019$, and the effective labor elasticity is given by $\alpha_{n} \tau_{n}\left(1-\alpha_{o} \tau_{n}\right)=0.9$. A doubling of the oil price can then lead to about a $3 \%$ decrease in output under the maintained assumption that labor decreases by just $1 \%$. Thus the multiplier effect of capacity utilization is approximately 1.3. This multiplier effect, however, is too small to account for the data. ${ }^{8}$

If we allow for externalities or increasing returns to scale in the capacity utilization model, although the size of the contemporaneous (or instantaneous) multiplier does not change dramatically for small externalities, an accelerator will emerge, giving rise to an intertemporal (or dynamic) multiplier. Under the intertemporal multiplier, output not only decreases in the impact period but also continues to decrease over time, leading to a deeper slump. For example, if $\eta=0.1$, the output elasticity of the oil price becomes 0.02 and the labor's elasticity becomes approximately 1.0. Hence, judged by the instantaneous multiplier, the total change in output is still roughly $3 \%$ in the impact period. But, under the influence of the intertemporal multiplier (i.e., the accelerator), output continues to decrease for several quarters before a trough is reached. Based on our parameter calibration, at the trough, output is about $8 \%$ below its initial value.

The cyclical propagation mechanism (or intertemporal multiplier) arises under externalities because firms' production decisions and investment activities reinforce each other, 
causing the aggregate economy to over-shoot the steady state as the economy converges. Such over-shooting behavior implies cycles. Consider a permanent increase in the oil price. The rise in the oil price increases the marginal cost of production at the firm level, hence reducing oil demand as well as employment and capacity utilization. This causes a contraction in output. Anticipating a lower future productivity of capital, firms also reduce investment spending, depressing aggregate demand and leading to a fall in the capital stock. Due to

the force of externalities among firms, this becomes a cumulative process of contractions. As the contraction continues, the rising marginal product of capital dictates that the decrease in output slow down (de-accelerate). The result is that sooner or later the capital stock and output must stop declining, and capacity utilization and investment must start to increase to exploit the excessively high marginal product of capital at a business-cycle trough. But then a rise in investment demand also triggers output expansion. Thus, the above propagation mechanism reverses itself, leading to a cumulative process of recovery and expansion.

\section{$3 \quad$ Empirical Evidence}

Although the model predicts that oil prices alone can explain the movements of the U.S. economy after the oil shocks in 1973-74, there is no prior reason to believe that this is indeed the case for the U.S. economy. It is, for example, entirely possible that non-oil shocks, such as monetary shocks, also contributed to the business cycle following the oil price increases in the early 70s. If this is the case, then being able to fully account for the deep recession by oil shocks alone may not be a good property for the model to have. Hence, empirically estimating the effects of the oil shocks in the early 70s on the U.S. economy can provide evidence to support (or reject) the model. Unfortunately, it is in general very difficult to identify the exact effect of oil shocks and non-oil shocks quantitatively in empirical studies because any such attempt via structural VARs inevitably involves identifying assumptions that are theory-loaded and hence may not necessarily be true. Therefore, the evidence provided in this section can only be viewed as circumstantial, and it serves only as a reference point for our theoretical analysis. More empirical studies are needed to further validate and reconfirm our findings. We focus our attention first on the effects of the OPEC oil embargo in 1973.

To study the effects of exogenous oil shocks on the U.S. economy, we first decompose movements in the price of imported oil into those driven by non-domestic (or exogenous) factors and those driven by domestic (or endogenous) factors. Econometric tests show that 
post-war oil prices, especially prior to the mid-80s, can be best described as random walks. Hence, our methodology for identifying the exogenous factors is based on a long-run restriction on the effect of an oil shock (e.g., the OPEC decision to raise the oil price) on the nominal oil price, following the econometric methodology of Blanchard and Quah (1989). We assume that an exogenous oil shock (such as the OPEC embargo) is an innovation that can have a permanent effect on the oil price, and that other factors, which may potentially have an impact on oil prices through demand-side effects, can only have transitory effects on the oil price. Based on this identifying assumption, our empirical result attributes more than $95 \%$ of the movements in the oil price to the exogenous oil shocks. This is consistent with a large body of empirical literature that has convincingly argued that post-war movements in oil prices (at least up to the mid-1980s) were largely exogenous to U.S. economic activity (see, e.g., Hamilton 1983 and the literature cited in the Introduction). Our identifying assumption is hence reasonable for the period we study.

Based on this identification assumption, we can also decompose movements in the U.S. economy into those driven by oil shocks and those driven by non-oil shocks. In order to best capture the effect of non-oil shocks on the U.S. economy, we have included several variables in our VAR: GDP, consumption, investment, and employment. Our results are robust when monetary policy variables, such as the interest rate and money supply, are included in the VAR. We do not impose prior restrictions on the impact of oil shocks on the other variables in the VAR, such as the output level. Instead, we allow the data to tell us how those U.S. variables respond to the oil shocks so identified.

The data used in our analysis are seasonally adjusted quarterly data starting in 1950:1 and ending in 1978:4, right before the second major oil shock hit the economy in 1979 (which is also a time when the economy had completely recovered to its pre-1973 shock level relative to the trend). The oil price data we use is the spot oil price of the West Texas Intermediate (available from the St. Louis Fed's website). The other data used are real GDP, real consumption for non-durables plus services, real fixed investment, and total nonfarm employment (available from the Bureau of Economic Analysis and the Bureau of Labor Statistics). All variables used in the VARs are logged and first-differenced. In other words, the growth rates are used in the VARs. A constant and 4 lags for each variable are included in the VAR estimation. Since we are only interested in the joint effects of the non-oil shocks (namely, we are not interested in further distinguishing the non-oil shocks from each other), how these non-oil shocks are individually identified does not matter. What matters are the identifications imposed on the non-oil shocks as a group. We therefore apply the Choleski 
triangularization to a long-run matrix to identify the sum of the non-oil shocks. To uncover the log levels of the time series, we integrate the growth rate series by adding a constant to each variable (based on the mean growth rates of the data) to induce a linear growth trend. ${ }^{9}$

The empirical results are reported in two figures. First, the identified effects of the nonoil shocks on output, consumption, investment, and employment are reported in Figure 4. We see that fluctuations driven by non-oil shocks track the actual movements in output, consumption, investment, and employment very well before the oil crisis (between 1950 and the early 1970s), suggesting that the oil shocks are not the main source of the business cycle for the entire period prior to $1973 .^{10}$ In other words, non-oil shocks have been mainly responsible for all of the business cycles in the U.S. from 1950 until 1973. Starting from 1974, however, the picture changes dramatically. Non-oil shocks are no longer able to explain the movements in output, consumption, investment and employment. This stunning fact can also be seen in Figure 5, which shows the sole effects of the oil shocks on the U.S. economy. There we see that, in complement to Figure 4, oil shocks have contributed very little to output fluctuations in the entire sample period prior to the recession 1974-75. Starting in 1974, however, oil shocks become the dominating force in movements of output, consumption, investment, and employment. These results are consistent with the predictions of our model using the actual oil price as the forcing variable.

Robustness: The model's predictions in the previous section and the VAR analysis in the current section are based on the nominal oil price. We have also simulated our model and estimated the VAR using the real oil price, defined as the ratio of the nominal oil price to the GDP deflator. The results are almost exactly the same as those obtained under the nominal oil price for both the theoretical model and the empirical VAR. ${ }^{11}$ In addition, we have also tried to follow the idea of Rotemberg and Woodford (1996) by identifying the component in the real oil price that is due to oil shocks in the nominal oil price. Then the movements in the real oil price due to the oil shocks are fed into our theoretical model. The predictions remain essentially the same.

We have also conducted robustness analysis on the identifying restrictions and the specifications used in the VARs. Bernanke et al. (1997) and especially Barsky and Kilian (2001) argue that monetary policy, instead of oil shocks, could have been responsible for the recession in 1975. Hence we have also re-estimated our measure of oil shocks and their impact on the U.S. economy by extending our VAR to include some measures of monetary policy (e.g., the growth rate of the money supply and the interest rate). Our empirical estimates of the impact of the oil shocks on the U.S. economy between 1950 and 1978 remain essentially 
unchanged when these measures of monetary policy are included in the VAR. Furthermore, very similar results are obtained if short-run identifying restrictions, instead of the long-run identifying restriction, are adopted for identifying the effect of oil shocks in the VARs. To preserve space, details of these results are not reported in the paper, but they are available upon request.

\section{The Second Oil Price Shock: 1979-1980}

In this section we extend our analysis beyond 1978 to 1984, studying the effects of the oil crisis in 1979-80. ${ }^{12}$ The predictions of our model for the effect of the second oil shock are presented in Figure 6 (top panel) where the investment series is selected as the focus. It shows that, although the model makes the correct prediction about the recession that follows the shock in 1979-80, it misses the temporary boom of the U.S. economy in 1981. Because of this, the model predicts a deep recession in 1981, but a deep recession in the actual economy did not arrive until late 1982. Similarly, the model predicts a strong recovery in late 1981 and beyond, about 5-6 quarters earlier than the actual recovery in and after 1983. The magnitude of the deep recession in late 1982, however, is well captured by the model, although the predicted one is about 5-6 quarters too early.

Therefore, according to our model, there must have been some non-oil shocks hitting the economy in 1981 that explain the sudden boom in 1981 and the consequent delays in the deep recession and the big recovery. The implication that some non-oil shocks may have been active during this period is confirmed by our VAR analysis in Figure 6 (bottom panel). ${ }^{13}$ The solid line in that figure represents the predicted effects of oil shocks identified in the VAR. It shows that in sharp contrast to the 1975 recession, oil shocks in 1979-80 cannot explain the sudden boom in 1981 and the postponed recession in late 1982. Instead, oil shocks predict a deep recession in 1981 and a strong recovery in 1982 and beyond, similar to the predictions of our general equilibrium model. Thus, our model still accords reasonably well with the experience of the early $80 \mathrm{~s}$.

Interestingly, such results, based on both the theoretical model and the empirical VARs, are remarkably consistent with the empirical findings of Hooker (1996). Based on an extensive empirical analysis that is independent and significantly different from ours, Hooker concludes that "historical decompositions indicate that the oil price shock of 1973 had a large and well-measured impact on the macroeconomy, while that of 1979 was significant but incomplete in capturing the dynamics of the 1980-82 recession" (Hooker 1996, p.211). 


\section{Concluding Remarks}

Standard models are not able to quantitatively account for the deep recession in the mid-70s when the actual oil price series is used for model simulations, despite the common belief that oil shocks in the 1970s are responsible for that recession. In this paper, we provide support for the importance of oil shocks in driving U.S. economic fluctuations in the 1970s. Our results strengthen the findings of a large body of empirical literature that suggests that the oil crisis in the early 1970s is responsible for the deep recession in 1975. We argue that the failure of standard models hinges on a missing multiplier-accelerator mechanism that serves to amplify and propagate the impact of oil shocks throughout the U.S. economy. We construct such a multiplier-accelerator mechanism in a general equilibrium model and show that the mechanism is capable of explaining the important features of the data. 


\section{References}

[1] Abel, Andrew B. and Ben S. Bernanke. (2001) Macroeconomics, 4th edition, Addison Wesley Longman, Inc.

[2] Aguiar-Conraria, Luís. and Yi Wen. (2004) "Foreign trade and equilibrium indeterminacy.", CAE Working Paper \#04-09, Cornell University.

[3] Barsky, Robert B. and Lutz Kilian. (2001) "Do we really know that oil caused the great stagflation? A monetary alternative." In Ben S. Bernanke and Kenneth S. Rogoff, eds., Macroeconomics Annual, Cambridge, MA: MIT Press for NBER, 137-183.

[4] Benhabib, Jess and Roger Farmer. (1994) "Indeterminacy and increasing returns." Journal of Economic Theory, 63, 19-41.

[5] Benhabib, Jess and Yi Wen. (2004) "Indeterminacy, aggregate demand, and the real business cycle." Journal of Monetary Economics, 51:3, 503-530.

[6] Bernanke, Ben S., Mark L. Gertler and Mark W. Watson. (1997) "Systematic monetary policy and the effects of oil price shocks." Brookings Papers on Economic Activity, 1, 91-142.

[7] Blanchard, Olivier. (2001) "Comment." In Ben S. Bernanke and Kenneth S. Rogoff, eds., Macroeconomics Annual, Cambridge, MA: MIT Press for NBER, 183-192.

[8] Blanchard, Olivier J. and Danny Quah, 1989, "The dynamic effects of aggregate demand and supply disturbances." American Economic Review, 79:4, 655-673.

[9] Blinder, Alan. (2001) "Comment." In Ben S. Bernanke and Kenneth S. Rogoff, eds., Macroeconomics Annual, Cambridge, MA: MIT Press for NBER, 192-197.

[10] Burbidge, John and Alan Harrison. (1984) "Testing for the effects of oil-price rises using vector autoregressions.", International Economic Review, 25:2, 459-484.

[11] Cass, David and Karl Shell. (1983) "Do sunspots matter?" Journal of Political Economy, 91:2, 193-227.

[12] Farmer, Roger. (1999) Macroeconomics of Self-fulfilling Prophecies, Second Edition, The MIT Press. 
[13] Finn, Mary. (2000) "Perfect competition and the effects of energy price increases on economic activity." Journal of Money, Credit, and Banking, 32:3, 400-417.

[14] Gisser, Micha and Thomas H. Goodwin. (1986) "Crude oil and the macroeconomy: Tests of some popular notions." Journal of Money, Credit, and Banking, 18:1, 95-103.

[15] Hamilton, James. (1983) "Oil and the macroeconomy since World War II." Journal of Political Economy, 91:2, 228-248.

[16] Hamilton, James. (1985) "Historical causes of postwar oil shocks and recessions." Energy Journal, 6, 97-116.

[17] Hamilton, James. (1988a) "A neoclassical model of unemployment and the business cycle." Journal of Political Economy, 96:3, 593-617.

[18] Hamilton, James. (1988b) "Are the macroeconomic effects of oil-price changes symmetric? A comment." Carnegie-Rochester Conference Series on Public Policy, 28 (Spring), 369-378.

[19] Hamilton, James. (1996) "This is what happened to the oil price-macroeconomy relationship.", Journal of Monetary Economics, 38:2, 215-220.

[20] Hamilton, James. (2003) "What is an oil shock?", Journal of Econometrics, 113:2, 363398.

[21] Hamilton, James and Ana Maria Herrera, 2004, "Oil Shocks and Aggregate Macroeconomic Behavior: The Role of Monetary Policy", Journal of Money, Credit, and Banking, $36: 2,265-286$.

[22] Hooker, Mark. (1996) "What happened to the oil price-macroeconomy relationship?" Journal of Monetary Economics, 38:2, 195-213.

[23] Hooker, Mark. (2002) "Are oil shocks inflationary? Asymmetric and nonlinear specifications versus changes in regime." Journal of Money, Credit, and Banking, 34:2, 540-561.

[24] Kim, In-Moo and Loungani, Prakash. (1992) "The role of energy in real business cycle models." Journal of Monetary Economics, 29:2, 173-189. 
[25] Laitner, John and Dmitriy Stolyarov. (2004) "Aggregate returns to scale and embodied technical change: Theory and measurement using stock market data." Journal of Monetary Economics, 51:1, 191-233.

[26] Leduc, Sylvain and Keith Sill. (2004) "A quantitative analysis of oil-price shocks, systematic monetary policy, and economic downturns." Journal of Monetary Economics, $51: 4,781-808$.

[27] Loungani, Prakash. (1986) "Oil price shocks and the dispersion hypothesis." Review of Economics and Statistics, 68:3, 536-539.

[28] Mork, Knut. (1989) "Oil and the macroeconomy when prices go up and down: An extension of Hamilton's results." Journal of Political Economy, 97:3, 740-744.

[29] Nordhaus, William. (2002) "The Economic Consequences of a War with Iraq." Yale University mimeo.

[30] Rasche, Robert H., and John A. Tatom. (1981) "Energy price shocks, aggregate supply and monetary policy: The theory and the international evidence." Carnegie-Rochester Conference Series on Public Policy, 14, 9-93.

[31] Rotemberg, Julio J. and Michael Woodford. (1996) "Imperfect competition and the effects of energy price increases on economic activity." Journal of Money, Credit, and Banking, 28:4, 549-577.

[32] Santini, Danilo. (1985) "The energy-squeeze model: Energy price dynamics in U.S. business cycles." International Journal of Energy Systems, 5:1, 159-194.

[33] Tatom, John. (1988) "Are the macroeconomic effects of oil price changes symmetric?" Carnegie-Rochester Conference Series on Public Policy, 28 (Spring), 325-368.

[34] Wen, Yi. (1998) "Capacity utilization under increasing returns to scale." Journal of Economic Theory, 81:1, 7-36. 


\section{Notes}

${ }^{1}$ This is especially true before the mid-1980s. See, for example, Rasche and Tatom (1981), Hamilton (1983, 1985, 1996, 2003), Burbidge and Harrison (1984), Santini (1985), Gisser and Goodwin (1986), Loungani (1986), Tatom (1988), Mork (1989), Hamilton and Herrera (2004), and many others. Also see the references in Rotemberg and Woodford (1996).

${ }^{2}$ Empirical tests show that post-war oil prices follow a random walk. This is especially true prior to the early 1980s. This suggests that oil price changes are permanent for the period we study.

${ }^{3}$ In a similar spirit, Bernanke et al. (1997) blame contractionary monetary policy conducted in 1974 for the deep recession in 1974-75. But see the skepticism raised against the monetary view by Blanchard (2001) and Blinder (2001). Leduc and Sill (2004) study the likely effects of monetary policy during that period using a calibrated model. However, their analysis falls short in addressing our questions because they do not use the historical time series of monetary shocks or oil shocks to reproduce the recession in the mid-1970s.

${ }^{4}$ Finn's (2000) model of capacity utilization is slightly different from this one, but the mechanisms are similar.

${ }^{5}$ See Cass and Shell (1983) for the early literature on sunspot-driven fluctuations.

${ }^{6}$ See Farmer (1999) and Benhabib and Wen (2004) for discussion on calibrating indeterminate models. Our results are robust to other choices of the initial value of output. For example, we can also assume that investment or employment has inertia so that $\hat{\imath}_{0}=0$ or $\hat{n}_{0}=0$, and the results do not change significantly.

${ }^{7}$ Finn (2000) shows that her model and the model of Rotemberg and Woodford (1996) give almost identical predictions.

${ }^{8}$ The reason that Finn's (2000) model has a large enough multiplier to match the depth of the recession is that she assumes a much larger oil share in the US aggregate production. Her calibration is equivalent to setting $\alpha_{o}=0.043$, implying an output elasticity of the oil price in the order of $\alpha_{o} \tau_{n} /\left(1-\alpha_{o} \tau_{n}\right) \approx 6 \%$. This elasticity, combined with a fall in labor, can account for the fall in output.

${ }^{9}$ Recall that the linear growth trends were removed during the VAR estimation since a constant is included in the VAR. 
${ }^{10}$ This does not imply that the oil shocks are not related to recessions prior to 1973 . The figure simply indicates that at a quantitative level, oil shocks on their own did not play a crucial role in U.S. economic activity prior to 1973.

${ }^{11}$ This is so because real oil prices move very closely with nominal oil prices in that period.

${ }^{12}$ We do not go beyond 1984 in our analysis because there is evidence of a structural change in the relation between oil and the rest of the economy in the mid-80s. In particular, after the mid-80s negative oil price shocks become frequent and tend not to have much effect on the economy due to the well-known asymmetry of oil shocks discussed by Hamilton (2003) and Mork (1989). Our model, like the model of Finn and that of Rotemberg and Woodford, implies a symmetric effect of oil shocks and is hence not suitable for analyzing the effects of oil shocks after the mid-80s.

${ }^{13}$ This is the VAR used earlier with the sample period extended to 1984. 

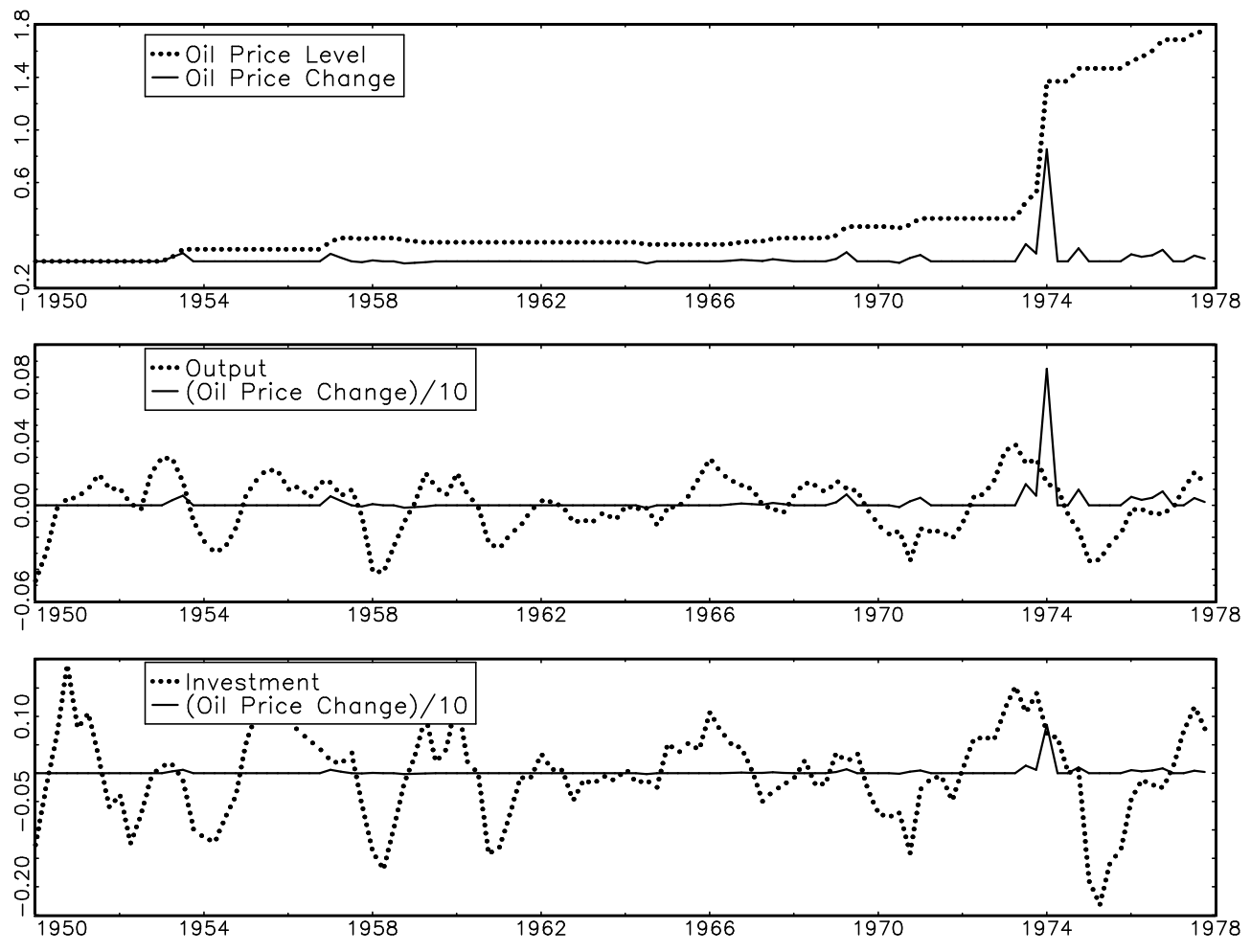

Figure 1. Oil Price and Economic Activity.
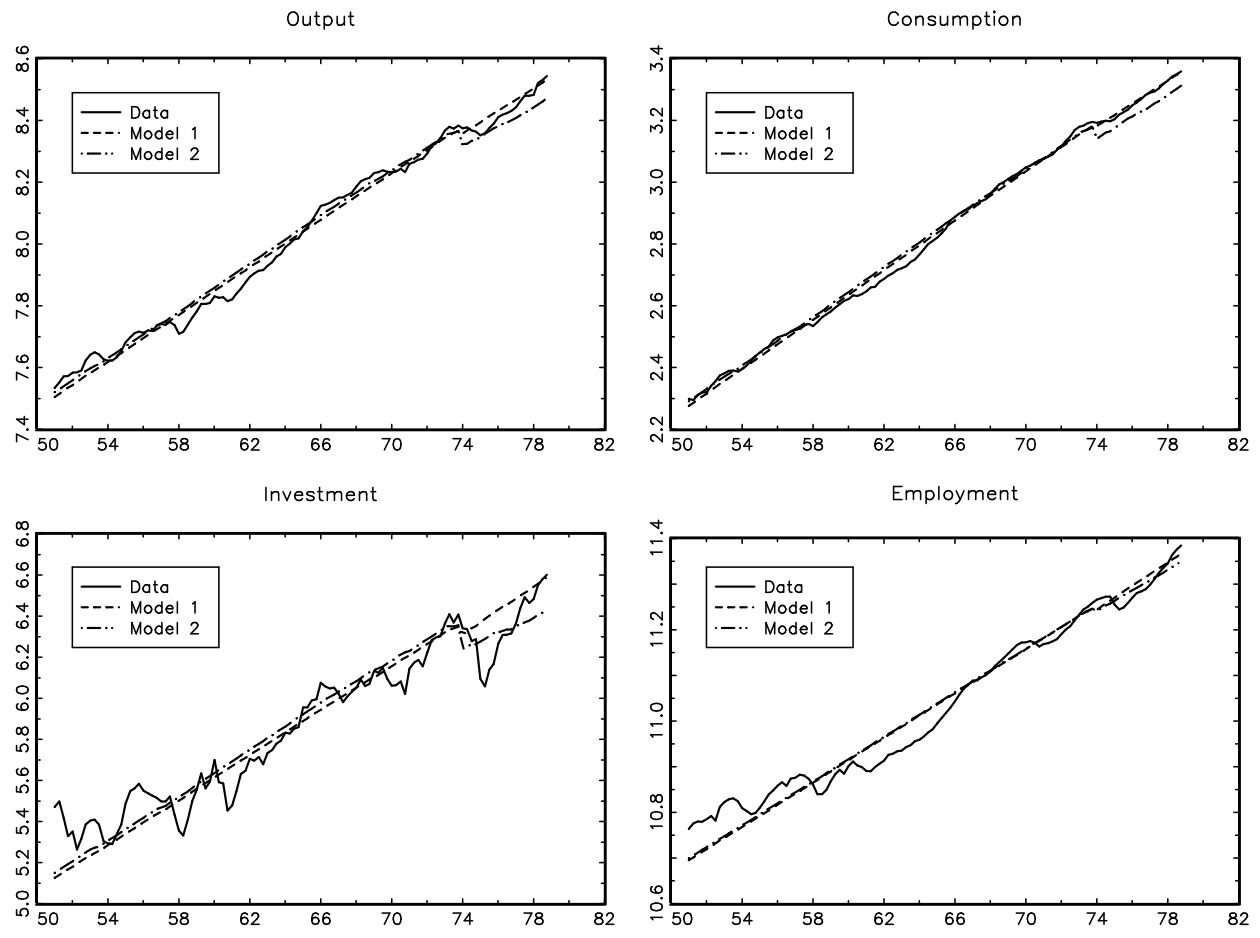

Figure 2. Predictions of a Standard RBC Model (1) and Finn's Model (2). 

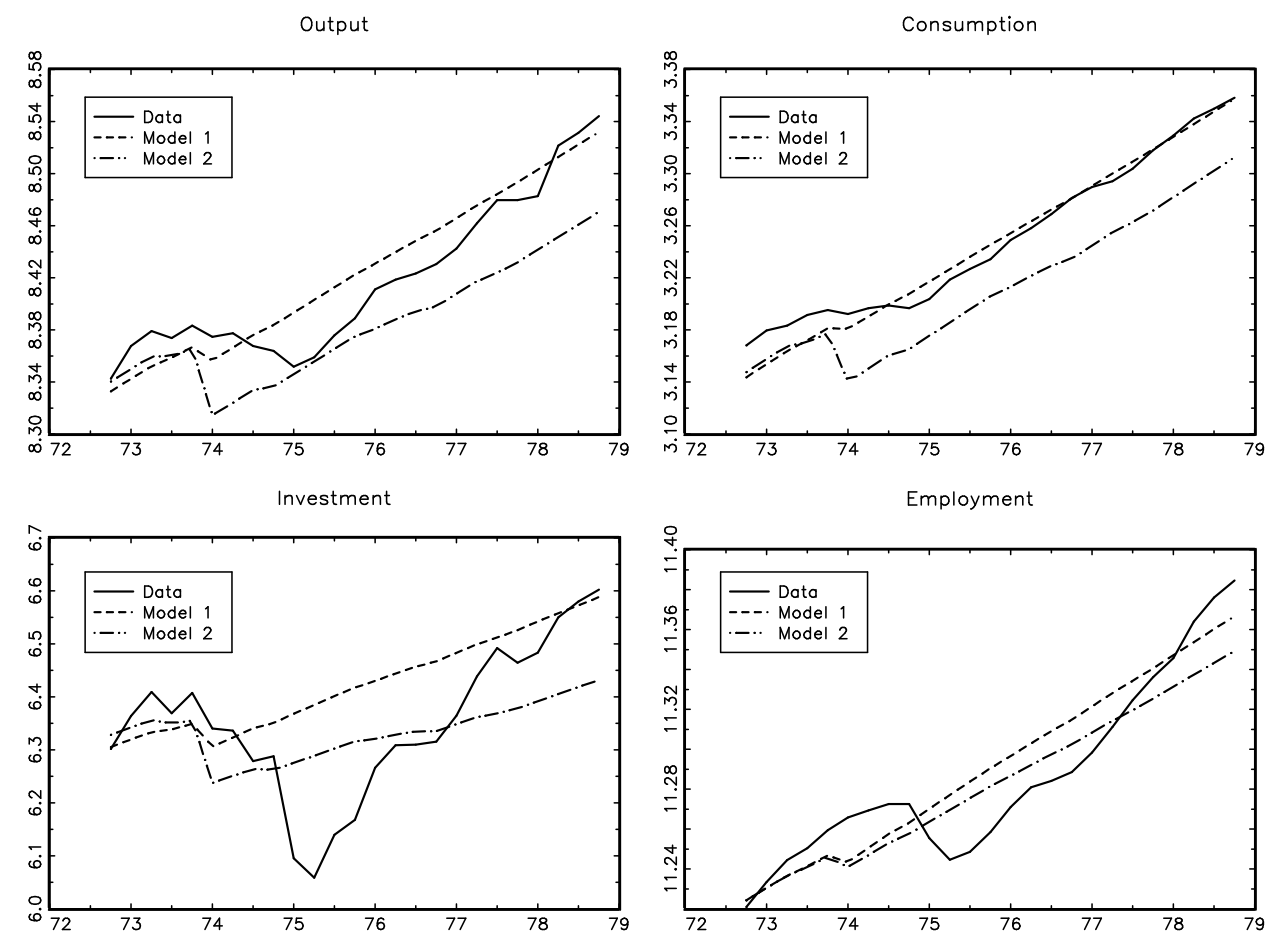

Figure 2-1. (A close up of Figure 2).
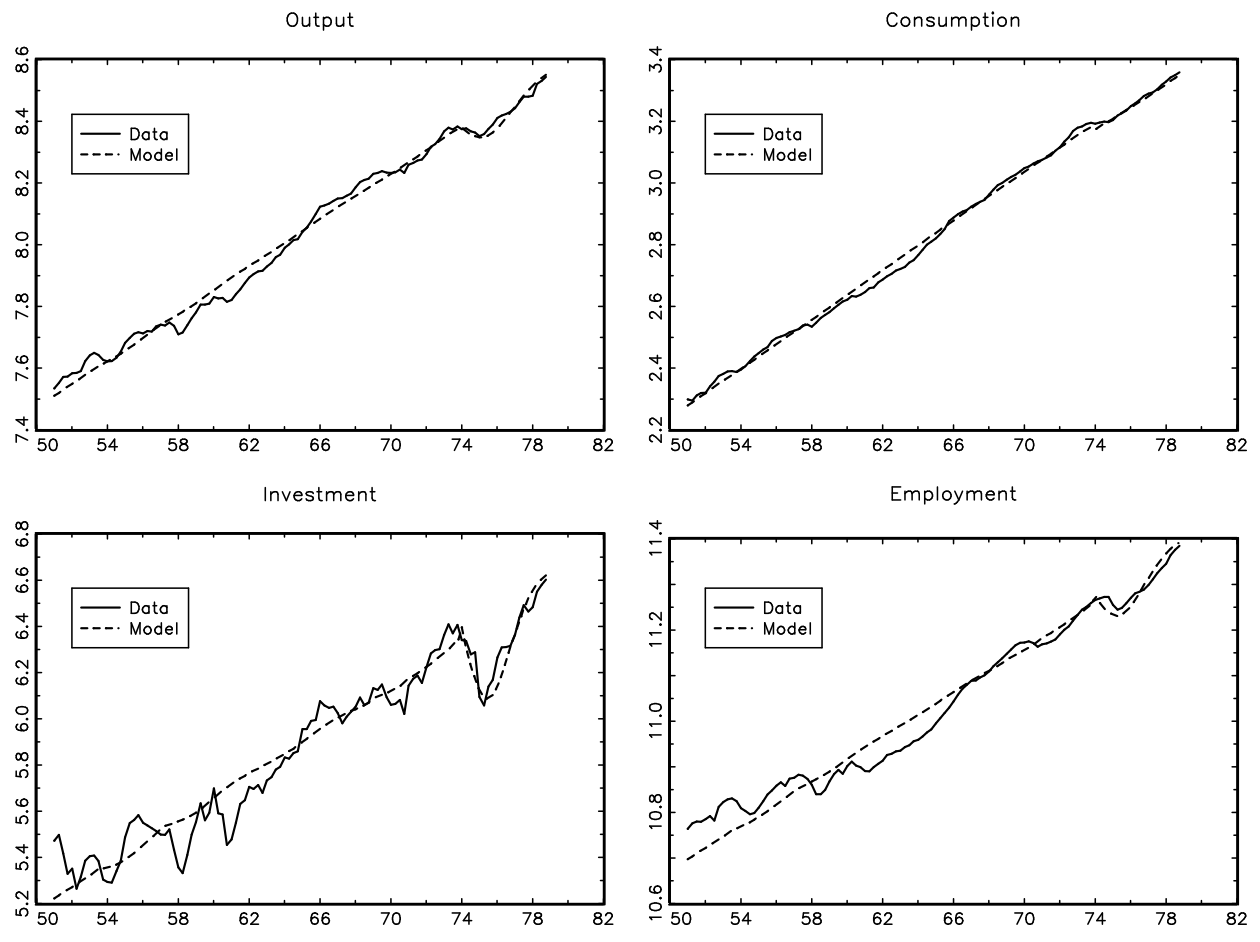

Figure 3. Predictions of Our Model. 

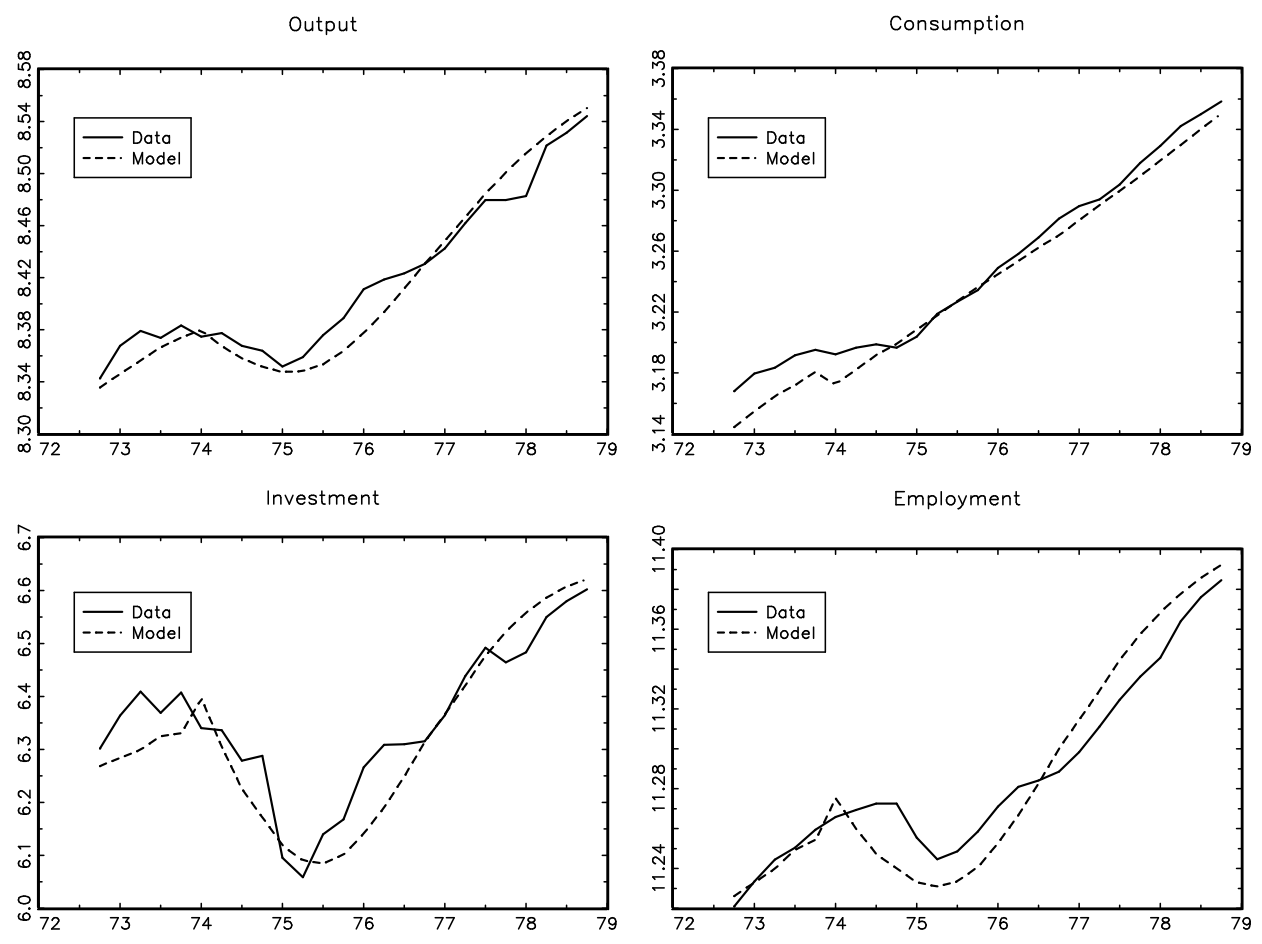

Figure 3-1. (A close up of Figure 3).
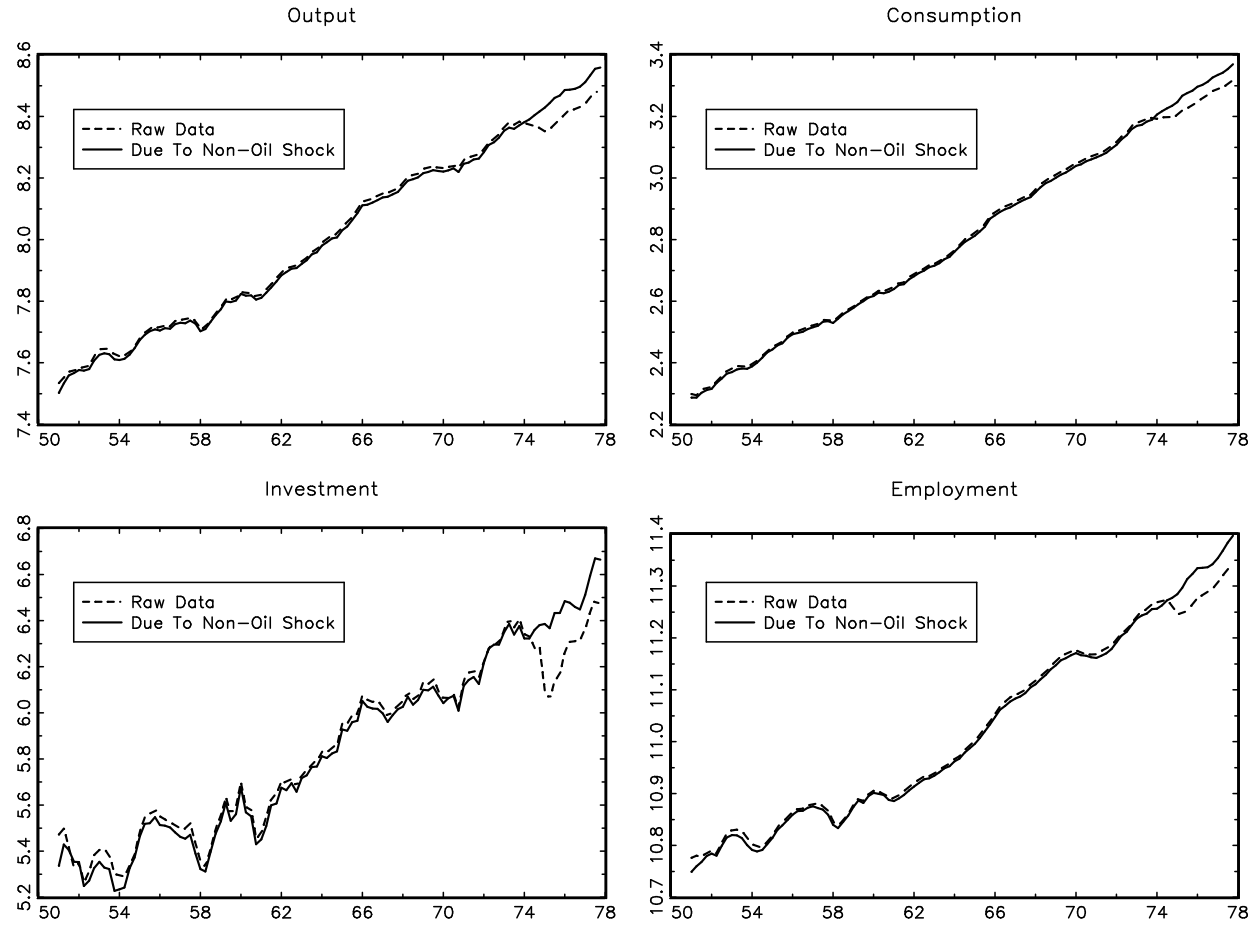

Figure 4. Effects of Non-Oil Shocks on the U.S. Economy (solid lines). 

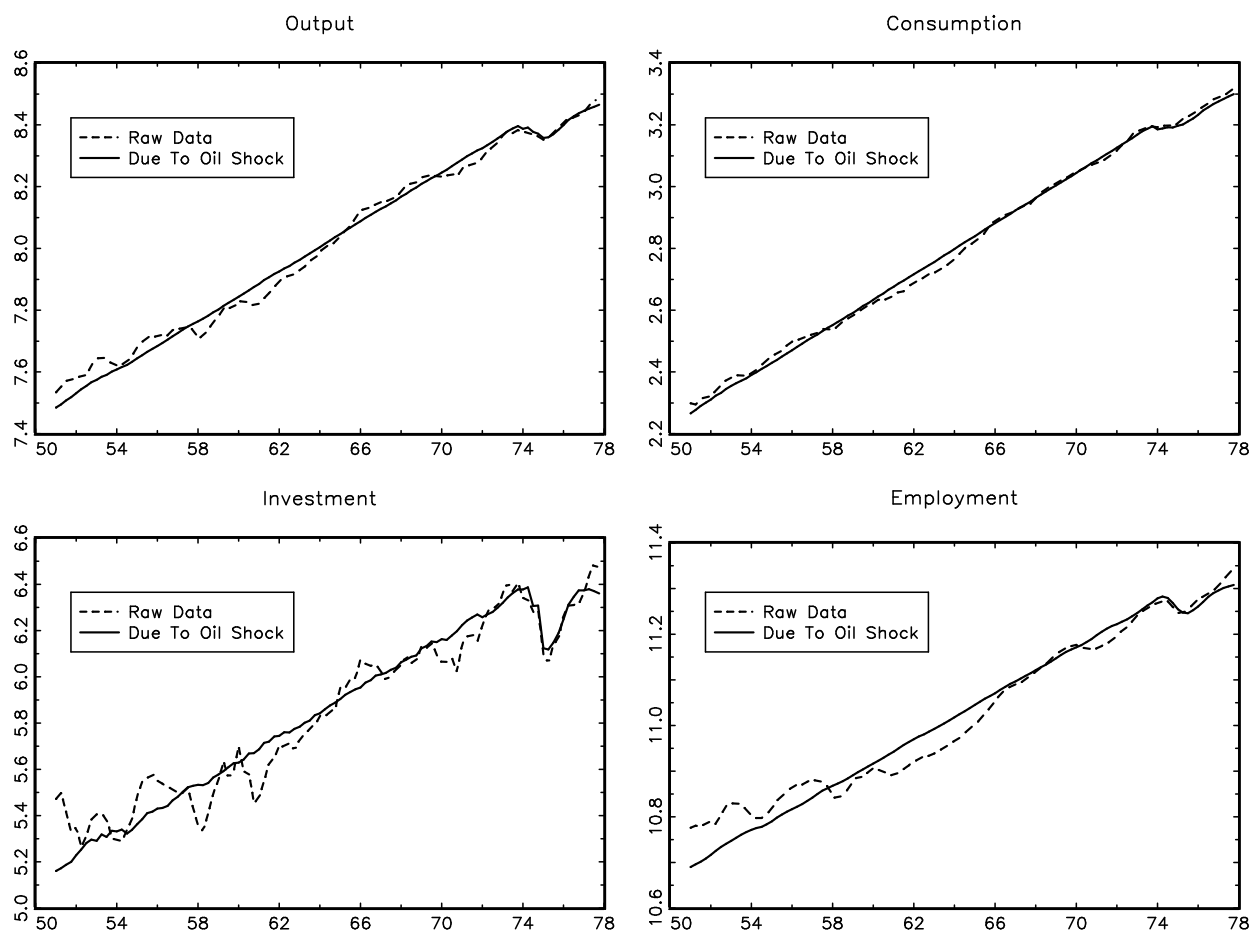

Figure 5. Effects of Oil Shocks on the U.S. Economy (solid lines).
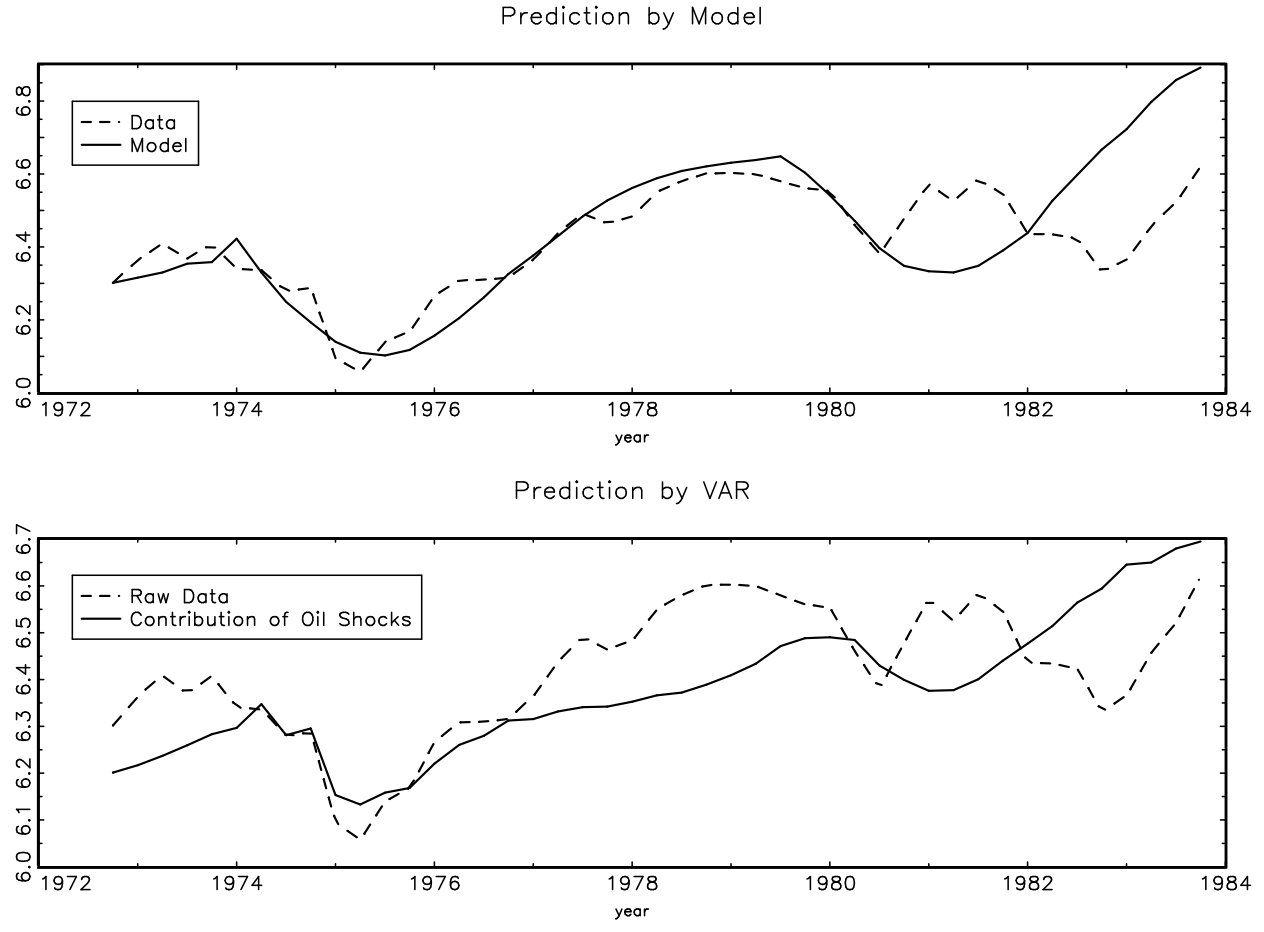

Figure 6. Predictions for the Second Oil Shock (solid lines). 
Table 1. Parameter Values

\begin{tabular}{c|c}
\hline \hline$\gamma=0$ & indivisible labor \\
$\beta=0.99$ & discount factor \\
$\theta=1.4$ & $\Rightarrow$ steady-state capital depreciation of $2.5 \%$ \\
$\alpha_{n}=0.7$ & labor's share \\
$\alpha_{o}=0.015$ & oil's share \\
$\alpha_{k}=1-\alpha_{n}-\alpha_{o}$ & capital's share \\
$1+\eta=1.108$ & returns to scale \\
\hline
\end{tabular}

